\title{
Interleukin-6, Tumor Necrosis Factor- $\alpha$, and High-sensitivity C-reactive Protein in Diabetic Patients with Helicobacter pylori in Kosovo
}

\author{
Greta Begolli-Stavileci ${ }^{1}$, Gramos Begolli ${ }^{2 *}$, Luljeta Begolli ${ }^{3}$ \\ ${ }^{1}$ Medical Laboratory "Bioticus", Prishtina, Kosovo; ${ }^{2}$ Department of Clinical Chemistry, Faculty of Medical, Josip Juraj Strossmayer \\ University of Osijek, Osijek, Croatia; ${ }^{3}$ Department of Clinical Biochemistry, Faculty of Medicine, University of Pristina, Prishtina, \\ Kosovo
}

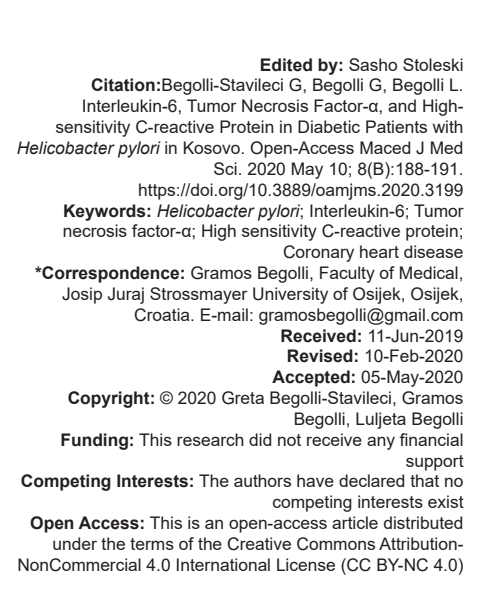

\begin{abstract}
Helicobacter pylori is a Gram-negative spiral-shaped bacterium that infects from $30 \%$ to $50 \%$ of the world's population and it is one of the most important in dyspeptic syndrome causes of gastritis and peptic ulcer. H. pylori is one of the most common chronic bacterial infections especially in the development countries because the socioeconomic contribute to chronic disease. The infection induces an acute polymorphonuclear infiltration in the gastric mucosa. Infection with $\mathrm{H}$. pylori has been epidemiologically linked to some extra digestive conditions, including ischemic heart disease, diabetes mellitus (DM), and others. The patients with DM are at risk for $H$. pylori infection, since they have coupled susceptibility of to a wide range of infections as a result of chronic elevation of blood glucose leve and impairment of immune functions. Chronic inflammation is a risk factor for coronary heart disease, because inflammation, vascular injury and thrombosis are considered to cause atherosclerosis. The risk of cardiovascular events is associated with increased levels of the acute phase proteins, C-reactive protein (CRP), and proinflammatory cytokines. Interleukin 6 (IL-6), a major pro-inflammatory cytokine is produced in a variety of tissues, including activated leukocytes, adipocytes, and endothelial cells. CRP is the principal downstream mediator of the acute phase response and is primarily derived through IL-6-dependent hepatic biosynthesis. Tumor necrosis factor- $\mathrm{C}$ (TNF- $\alpha$ ), as an important inflammatory factor, has been shown to play a central role in the pathogenesis of diabetes. CRP and IL-6 were determinant of risk for the development of type 2 DM in apparently healthy middle-aged women. Since the prevalence of infected persons with $\mathrm{H}$. pylori in Kosovo is high, the aim of this study was the evaluation of cytokines (IL1, TNF-a) and CRP in diabetic type 2 patients with positive H. pylori.
\end{abstract}

\section{Introduction}

Helicobacter pylori is one of the most common chronic bacterial infections in the world, especially in the development countries because the socioeconomic status contribute to chronic disease [1], [26]. Infection with $H$. pylori $(H$. pylori is a Gram-negative bacteria) has been epidemiologically linked to some extra digestive conditions, including ischemic heart disease, diabetes mellitus (DM), neurological disease, gynecological disease, ophthalmology, skin, and oral mucosa disease, respiratory, ear, nose and throat disease, and hematologic disease [2].

The patients with DM are at risk for $H$. pylori infection [3], since they have coupled susceptibility of to a wide range of infections because of chronic elevation of blood glucose level and impairment of immune functions [4].

Chronic inflammation is a risk factor for coronary heart disease, because inflammation, vascular injury and thrombosis are considered to cause atherosclerosis [5], [6], [7], [8]. The risk of cardiovascular events is associated with increased levels of the acute phase proteins, C-reactive protein (CRP), and proinflammatory cytokines [9].

Interleukin 6 (IL-6), a major pro-inflammatory cytokine, is produced in a variety of tissues, including activated leukocytes, adipocytes, and endothelial cells. CRP is the principal downstream mediator of the acute phase response and is primarily derived through IL-6-dependent hepatic biosynthesis. Tumor necrosis factor- $\alpha$ (TNF- $\alpha)$, as an important inflammatory factor, has been shown to play a central role in the pathogenesis of diabetes [10].

CRP and IL-6 were determinant of risk for the development of type $2 \mathrm{DM}$ in apparently healthy middleaged women [11].

Since the prevalence of infected persons with H. pylori in Kosovo is high, the aim of this study was the evaluation of cytokines (IL-6, and TNF- $\alpha$ ) and CRP in diabetic type 2 patients with positive $H$. pylori. 


\section{Methods}

\section{Study subject}

The study was an observational study performed through case-control method in which was two identify groups one as a study group and one as a control group conducted from January 2017 to January 2019

The patients diagnosed with diabetes type 2 were selected in the Internal Clinics of University Clinical Centre of Kosovo, whereas the samples analysis took place in the Medical Laboratory "Bioticus" in Kosovo.

The following subjects were excluded from this study: Pregnant woman, patients with antibiotic treatment or any other medication known to affect the inflammatory markers and those with any diagnosed systematic disease. The study was performed in compliance with human - studies guidelines and all participants were informed about the study and the nature of procedure was explained.

\section{Detailed analysis}

Blood was obtained from each participant subject by venipuncture using tubes without anticoagulant. After this, the tube was immediately transferred for centrifugation at $2000 \mathrm{rpm}$ for $10 \mathrm{~min}$ and transferred into Eppendorf tubes and stored at temperature $-20^{\circ} \mathrm{C}$.

Serum samples were obtained for the determination of $H$. pylori antibodies, specific immunoglobulin $\mathrm{G}(\mathrm{IgG})$ antibodies with a specific high sensitivity method using the enzyme-linked fluorescent assay technique in an automated instrument of the Vidas Family a Mini Vidas (bioMerieux, Vitek, France).

For IL-6, TNF $-\alpha$, and high sensitivity CRP (hs-CRP) serum samples were assessed using a kit with a specific high sensitivity methodology - ELISA test, according to the manufacturer's instructions (IBL International $\mathrm{GmbH}$, Hamburg, Germany).

\section{Statistical analysis}

Statistical analysis was analyzed with the Vassar-Stats system. T-test was conducted and the average, correlation ( $r$ ) and standard deviation were counted. These results are shown in the table presentation. The differences in control group and study group were compared using the Student's t-test of mean value. The average and standard deviation were assessed for IL-6, TNF- $\alpha$, and hs-CRP. The correlation of IL-6, TNF- $\alpha$, and hs-CRP was compared between diabetic patients with $H$. pylori positive and healthy subject. Differences were considered significant when $p<0.05$

\section{Results}

Eighty participants were enrolled in this study aged between 40 and 60 years old both gender.

All participants were divided in two groups. The first study group contains 50 patients, 30 male and 20 female who were identified as a diabetic type 2 patients with regular oral or parenteral therapy and also positive $H$. pylori lgG antibodies and control group which contains 30 subjects which were identified as healthy subject with no disease.

Control group was healthy subjects without any clinical signs related to diabetes and $H$. pylori.

Mean values in diabetic patients and control group are shown in Figure 1.

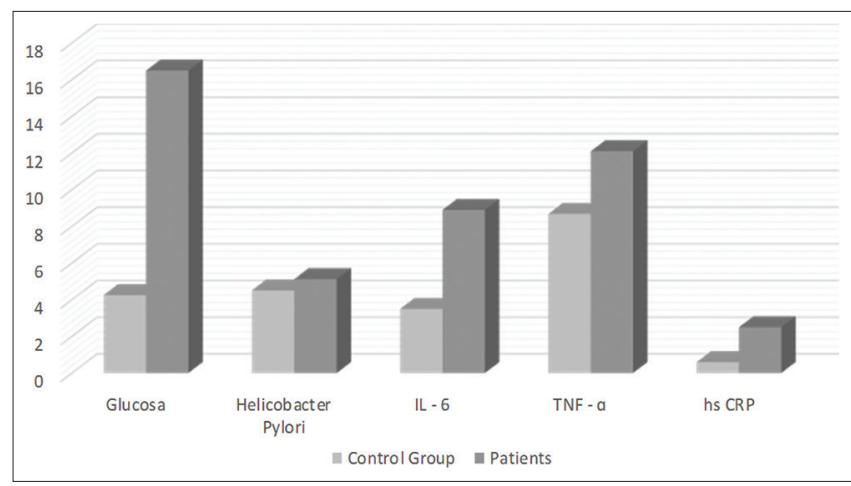

Figure 1: The comparison of mean values in patients and control group

Comparisons of inflammatory values in diabetic patients with $H$. pylori positive and control group are summarized in Table 1.

Table 1: Inflammatory markers in patients and control groups

\begin{tabular}{|c|c|c|c|}
\hline Parameters & Healthy $n=30$ & Diabetic with $H$. pylori $\mathrm{n}=50$ & $p$-value \\
\hline Age (years, mean $\pm S D$ ) & $42.13 \pm 1.92$ & $52.22 \pm 4.66$ & \\
\hline \multicolumn{4}{|l|}{ Gender n \% } \\
\hline Female & $14(47)$ & $20(40)$ & \\
\hline Male & $16(53)$ & $30(60)$ & \\
\hline \multicolumn{4}{|l|}{ Glucose } \\
\hline \multirow{2}{*}{\multicolumn{4}{|c|}{ H. pylori IgG }} \\
\hline & & & \\
\hline \multicolumn{4}{|l|}{ IL-6 } \\
\hline $\begin{array}{l}\text { Mean } \pm \text { SD } \\
\text { TNF-a }\end{array}$ & $3.5 \pm 1.1$ & $8.9 \pm 14.3$ & $0.02^{*}$ \\
\hline $\begin{array}{l}\text { Mean } \pm \text { SD } \\
\text { hs-CRP }\end{array}$ & $8.68 \pm 6.19$ & $12.1 \pm 8.7$ & $0.04^{*}$ \\
\hline Mean $\pm S D$ & $0.6 \pm 0.5$ & $2.5 \pm 2.6$ & $0.001^{*}$ \\
\hline
\end{tabular}

Statistical analysis was shown a significant difference of inflammatory cytokines in healthy subject and those diabetes patient with $\mathrm{H}$. pylori positive with regard to the levels of IL-6 $(3.5 \pm 1.1$ vs. $8.9 \pm 14.3$, respectively, $p<0.02)$ and TNF- $\alpha(8.68 \pm 6.19$ vs. 12.1 \pm 8.7 , respectively, $p<0.04$.

The mean serum level of hs-CRP was significantly higher $p<0.001$ in diabetic patient with $H$. pylori than in healthy subject $(2.5 \pm 2.6$ vs. $0.6 \pm 0.5)$.

We found also the correlation and significance between parameters in patients and control group (Table 2). 
Table 2: Correlation and significance between parameters in patients and control group

\begin{tabular}{|c|c|c|c|c|}
\hline \multirow[t]{2}{*}{ Correlation } & \multicolumn{2}{|c|}{ Control group } & \multicolumn{2}{|c|}{ Diabetic with H. pylori } \\
\hline & $\mathrm{R}$ & $\mathrm{p}$-value & $\mathrm{r}$ & $\mathrm{p}$-value \\
\hline HPY/IL-6 & - & - & 0.49 & $0.005^{*}$ \\
\hline HPY/TNF-a & - & - & 0.02 & 0.44 \\
\hline HPY/hs-CRP & - & - & 0.56 & $0.001^{*}$ \\
\hline IL-6/TNF-a & -0.06 & 0.37 & 0.23 & 0.11 \\
\hline IL-6/hs-CRP & 0.07 & 0.34 & 0.48 & $0.004^{*}$ \\
\hline TNF-a/hs-CRP & -0.12 & 0.25 & 0.08 & 0.33 \\
\hline
\end{tabular}

TNF-a: Tumor necrosis factor-alpha, hs-CRP: High sensitive C reactive protein, H. pylori: Helicobacter pylor

\section{Discussion}

H. pylori may have an impact on cardiovascular conditions and metabolic syndrome [12], [13], [14]. Several studies have evaluated the relation of $H$. pylori infection with coronary artery disease; a study done by Kowalski concluded that there is a significant link between coronary artery disease and infection with $H$. pylori [15]. A study by Bener et al. [16] suggested that there is a significant association between $H$. pylori infection and Type $2 \mathrm{DM}$ and interestingly, this infection is significantly higher in diabetic obese patients.

$H$. pylori infection stimulates the production of proinflammatory cytokines [27] potentially mediated by elevated inflammatory markers such as reactive protein C (CRP) [17], [18], [19] and interleukin (IL)-6. Inflammation and activated innate immunity have also been implicated in the pathogenesis of diabetes through insulin resistance [20], [21]. For example, elevated levels of inflammatory cytokines may lead to phosphorylation of serine residues on the insulin receptor substrate, which prevent its interaction with insulin receptors, inhibiting insulin action. Lipopolysaccharides from pathogens in the gut, such as $H$. pylori, have also been linked to the activation of toll-like receptors, resulting in energy harvesting, fat accumulation and stimulation of the innate immune system, and consequent insulin resistance [22], [23].

Low socioeconomic status includes chronic infections such as infection with $H$. pylori. Other contributor as risk factors are poor diet, smoking and physical inactivity are well-known contributors to the disparity, but only partially explain the gap in health states.

Based in literature $H$. pylori infection caused increase of inflammatory cytokines and CRP [17], [18], [19].

The results of some studies have shown that there is a higher prevalence of $H$. pylori infection in patients with DM type 2 in comparison to control group [6], [8], [16], [24], [25], [26], [27].

Infection with $H$. pylori was found in the previous studies to be correlated with elevated levels of CRP, IL-6, and TNF- $\alpha$ which are markers of inflammation implicated in insulin resistance and development of diabetes [9], [21].
The goals of this investigation were to compare the mean levels of TNF- $\alpha$, IL- 6 , and hs-CRP in serum samples of healthy subjects and diabetic subjects seropositive $H$. pylori. The studied cytokines were found to be increased in patient group compared to their levels in the healthy subjects. In addition, our study suggests that the gastric epithelial cells contribute substantially to the pro-inflammatory cytokine response to $H$. pylori infection, either by active cytokine production or by uptake of cytokines produced by the lamina propria or intraepithelial leukocytes [19]. It is very important to emphasize that this is the first study conducted in Kosovo estimating serum hs-CRP, IL-6, and TNF-a levels in diabetic patients with positive $H$. pylori and healthy persons, to have general information on the Kosovo population and connection with inflammatory markers.

\section{Conclusion}

H. pylori may have an impact on cardiovascular conditions and metabolic syndrome potentially mediated by elevations in inflammatory markers such as CRP and IL-6. Inflammation and activated innate immunity have also been implicated in the pathogenesis of diabetes through insulin resistance.

\section{Acknowledgments}

We thank the personnel of the Institute of Biochemistry-University of Prishtina and personnel of Medical Laboratory "Bioticus" for their support during this study.

\section{References}

1. Kannan M, Ramani R, Kumar EK. Prevalence of Helicobacter pylori in relation to socioeconomic status. Int J Sci Res. 2019;8(3):1802-4. Available from: http://worldwidejournals. co.in/index.php/ijsr/article/view/1802/1804.

2. Suzuki H, Franceschi F, Nishizawa T, Gasbarrini A. Extragastric manifestations of Helicobacter pylori infection. Helicobacter. 2011;16 Suppl 1:65-9. https://doi. org/10.1111/j.1523-5378.2011.00883.x

PMid:21896088

3. Samaropoulos XF, Light L, Ambrosius WT, Marcovina SM, Probstfield J, Goff DC Jr. The effect of intensive risk factor management in Type 2 diabetes on inflammatory biomarkers. Diabetes Res Clin Pract. 2012;95(3):389-98. https://doi. org/10.1016/j.diabres.2011.09.027

PMid:22019270 
4. Peach HG, Barntt NE. Helicobacter pylori infection and fasting plasma glucose concentracio. J Clin Pathol. 2001;54:466-9.

5. Rahman A, Cope MB, Sarker SA, Garvey WT, Chaudhury HS, Khaled MA. Helicobacter pylori infection and inflammation: Implications for pathophysiology of diabetes mellitus and coronary heart disease. J Life Sci. 2009;1(1):45-50. https://doi. org/10.1080/09751270.2009.11885133

PMid:22308070

6. Ojetti V, Pellicano R, Fagoonee S, Migneco A, Berrutti M, Gasbarrini A. Helicobacter pylori infection and diabetes. Minerva Med. 2010;101(2):115-9.

PMid:20467410

7. Diomedi M, Stanzione P, Sallustio F, Leone G, Renna A, Misaggi $G$, et al. Cytotoxin-associated gene-a-positive Helicobacter pylori strains infection increases the risk of recurrent atherosclerotic stroke. Helicobacter. 2008;13(6):52531. https://doi.org/10.1111/j.1523-5378.2008.00627.x PMid: 19166418

8. Hamed SA, Amine NF, Galal GM, Helal SR, Tag El-Din LM, Shawky OA, et al. Vascular risks and complications in diabetes mellitus: The role of Helicobacter pylori infection. J Stroke Cerebrovasc Dis. 2008;17(2):86-94. https://doi.org/10.1016/j. jstrokecerebrovasdis.2007.10.006

PMid:18346651

9. Ishida Y, Suzuki K, Taki K, Niwa T, Kurotsuchi S, Ando H, et al. Significant association between Helicobacter pylori infection and serum C-reactive protein. Int J Med Sci. 2008;5(4):224-9. https://doi.org/10.7150/ijms.5.224

PMid: 19230307

10. Pickup JC, Chusney GD, Thomas SM, Burt D. Plasma interleukin-6, tumour necrosis factor alpha and blood cytokine production in Type 2 diabetes. Life Sci. 2000;67(3):291-300. https://doi.org/10.1016/s0024-3205(00)00622-6 PMid:10983873

11. Hu FB, Meigs JB, Li TY, Rifai N, Manson JE. Inflammatory markers and risk of developing Type 2 diabetes in women. Diabetes. 2004;53(3):693-700. https://doi.org/10.2337/ diabetes.53.3.693 PMid: 14988254

12. Albaker WI. Helicobacter pylori infection and its relationship to metabolic syndrome: Is it a myth or fact? Saudi J Gastroenterol. 2011;17(3):165-9. https://doi.org/10.4103/1319-3767.80377 PMid:21546717

13. El Hadidy EH, Abdul-Aziz MY, Mokhtar AR. Helicobacter pylori infection and vascular complications in patients with Type 2 diabetes mellitus. J Taibah Univ Med Sci. 2009;4(1):62-72. https://doi.org/10.1016/s1658-3612(09)70082-4

14. Gunji T, Matsuhashi N, Sato H, Fujibayashi K, Okumura M, Sasabe $\mathrm{N}$, et al. Helicobacter pylori infection is significantly associated with metabolic syndrome in the Japanese population. Am. J Gastroenterol. 2008;103(12):3005-10. https:// doi.org/10.1111/j.1572-0241.2008.02151.x

PMid: 19086952

15. Kowalski M. Helicobacter pylori $(H$. pylori) infection in coronary artery disease: Influence of $H$. pylori eradication on coronary artery lumen after percutaneous transluminal coronary angioplasty. The detection of $H$. pylori specific DNA in human coronary atherosclerotic plaque. J Physiol Pharmacol. 2001;52 Suppl 1:3-31. https://doi.org/10.1016/ s1590-8658(01)80711-8

PMid:11795863
16. Bener A, Micallef R, Afifi M, Derbala M, Al-Mulla HM, Usman MA. Association between Type 2 diabetes mellitus and Helicobacter pylori infection. Turk J Gastroenterol. 2007;18(4):225-9.

PMid: 18080918

17. Pradhan AD, Manson JE, Rifai N, Buring JE, Ridker PM C-reactive protein, interleukin 6 , and risk of developing Type 2 diabetes mellitus. JAMA. 2001;286(3):327-34. https://doi. org/10.1001/jama.286.3.327

PMid:11466099

18. Shelbaya S, Amer H, Seddik S, Allah AA, Sabry IM, Mohamed T, et al. Study of the role of Interleukin-6 and highly sensitive C-reactive protein in diabetic ephropathy in Type 1 diabetic patients. Eur Rev Med Pharmacol Sci. 2012;16:176-82.

PMid:22428468

19. Nakagawa H, Tamura T, Mitsuda $Y$, Goto $Y$, Kamiya $Y$, Kondo $T$, et al. Significant association between serum interleukin-6 and Helicobacter pylori antibody levels among $H$. pylori-positive Japanese adults. Mediators Inflamm. 2013;2013:142358. https://doi.org/10.1155/2013/142358

PMid:24453409

20. Howard BV, Best L, Comuzzie A, Ebbesson SO, Epstein SE, Fabsitz RR, et al. C-reactive protein, insulin resistance, and metabolic syndrome in a population with a high burden of subclinical infection: Insights from the genetics of coronary artery disease in Alaska natives (GOCADAN) study. Diabetes Care. 2008;31(12):2312-4 https://doi.org/10.2337/dc08-0815 PMid: 18796618

21. Aydemir S, Bayraktaroglu T, Sert M, Sokmen C, Atmaca H, Mungan G, et al. The effect of Helicobacter pylori on insulin resistance. Dig Dis Sci. 2005;50(11):2090-3. https://doi. org/10.1007/s10620-005-3012-z PMid: 16240220

22. Manco M, Putignani I, Bottazzo GF. Gut microbiota, lipopolysaccharides and innate immunity in the pathogenesis of obesity and cardiovascular risk. Endocr Rev. 2010;31(6):81744. https://doi.org/10.1210/er.2009-0030

\section{PMid:20592272}

23. Fresno M1, Alvarez R, Cuesta N. Toll-like receptors, inflammation, metabolism and obesity. Arch Physiol Biochem. 2011;117(3):15164. https://doi.org/10.3109/13813455.2011.562514

PMid:21599616

24. Devrajani BR, Shah SZ, Soomro AA, Devrajani T. Type 2 diabetes mellitus; A risk factor for Helicobacter pylori infection; A hospital based case-control study. Int J Diabetes Dev Ctries. 2010;30(1):22-6. https://doi.org/10.4103/0973-3930.60008 PMid:20431802

25. Nodoushan SA, Nabavi A. The Interaction of Helicobacter pylori infection and Type 2 diabetes mellitus. Adv Biomed Res. 2019;8:15. https://doi.org/10.4103/abr.abr_37_18 PMid:30993085

26. Nicholas SB, Kalantar-Zadeh K, Norris KC. Socioeconomic disparities in chronic kidney disease. Adv Chronic Kidney Dis. 2015;22(1):6-15. https://doi.org/10.1053/j.ackd.2014.07.002 PMid:25573507

27. Jeon CY, Haan MN, Cheng C, Clayton ER, Mayeda ER, Miller JW, et al. Helicobacter pylori infection is associated with an increased rate of diabetes. Diabetes Care. 2012;35(3):520-5. https://doi.org/10.2337/dc12-0440

PMid:22279028 